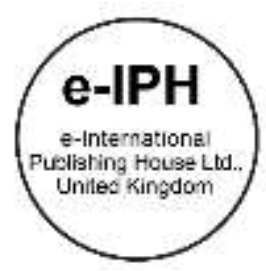

\title{
The Relationship of Sensory Design towards the Physical Learning Environment for Autism Classroom
}

\author{
Roslinda Ghazali ${ }^{1}$, Siti Rasidah Md Sakip ${ }^{2}$, Ismail Samsuddin ${ }^{3}$, Heba Samra 4 \\ 1 Department of Post-graduate, Faculty of Architecture, Planning \& Surveying, Universiti Teknologi MARA Perak Branch, \\ Seri Iskandar Campus, 32610, Perak, Malaysia. \\ ${ }^{2}$ Department of Landscape Architecture, Faculty of Architecture, Planning \& Surveying, Universiti Teknologi MARA Perak Branch, \\ Seri Iskandar Campus, 32610, Perak, Malaysia \\ ${ }^{2}$ Green Safe Cities Research Group, Universiti Teknologi MARA, Shah Alam Campus,40450, Selangor, Malaysia. \\ ${ }^{3}$ Department of Architecture, Faculty of Architecture, Planning \& Surveying, Universiti Teknologi MARA Perak Branch, \\ Seri Iskandar Campus, 32610, Perak, Malaysia. \\ ${ }^{4}$ Faculty of Fine Arts, Helwan University Cairo - Zamalek, 4 Mohamed Thakeb. St Zamalek, Cairo, Egypt.
}

lindakeruing@gmail.com, sitir704@perak.uitm.edu.my,

ismai578@uitm.edu.my, Heba.abdelhafeez@f-arts.helwan.edu.eg Tel: $013-5185148$

\begin{abstract}
Designing spaces for the autistic should be considered their sensory needs. This quantitative study employed the survey method to explore the relationship between the sensory design towards the physical learning environment. The respondents $(n=384)$ identified and Statistical Program for Social Sciences Software (SPSS) used for data entry and analysis. Pearson's Correlation is used to highlight relationships between the variables. The result revealed sensory design have a strong significant relationship with the physical learning environment in the context of autism. Findings hoped to benefit in creating to improve the autism learning environment in Malaysia.
\end{abstract}

Keywords: Sensory design; physical learning environment; quantitative

eISSN: 2398-4287@ 2021. The Authors. Published for AMER ABRA cE-Bs by e-International Publishing House, Ltd., UK. This is an open access article under the CC BYNCND license (http://creativecommons.org/licenses/by-nc-nd/4.0/). Peer-review under responsibility of AMER (Association of Malaysian Environment-Behaviour Researchers), ABRA (Association of Behavioural Researchers on Asians/Africans/Arabians) and cE-Bs (Centre for Environment-Behaviour Studies), Faculty of Architecture, Planning \& Surveying, Universiti Teknologi MARA, Malaysia. DOI: https://doi.org/10.21834/ebpj.v6i18.3070

\subsection{Introduction}

Autism Spectrum Disorder (ASD) is challenged by impairments in social interactions and communication, rigid behaviour and thinking, and lack of emotional understanding. Children with autism exhibit inattention and distractibility more than normal children. Every autistic child has different academic problems, such as difficulties in-class participation, low attention span, and inappropriate behaviours that hinder their ability to participate in educational activities. Hence, they usually experience disappointment in academic progress by ignoring proper changes in the environment may have severe negative impacts on the learning processes of autistic children. The learning environment has become significant because research has proven that the quality of educational facilities affects learning outcomes and the individuals within the building (Nazri \& Ismail, 2016). To enhance the development of children with autism, it is essential to ensure that the building is effective, convenient, fit and feasible for all children to use, especially for children with autism (Martin, 2014). There are only a few

eISSN: 2398-4287@ 2021. The Authors. Published for AMER ABRA cE-Bs by e-International Publishing House, Ltd., UK. This is an open access article under the CC BYNCND license (http://creativecommons.org/licenses/by-nc-nd/4.0/). Peer-review under responsibility of AMER (Association of Malaysian Environment-Behaviour Researchers), ABRA (Association of Behavioural Researchers on Asians/Africans/Arabians) and cE-Bs (Centre for Environment-Behaviour Studies), Faculty of Architecture, Planning \& Surveying, Universiti Teknologi MARA, Malaysia.

DOI: https://doi.org/10.21834/ebpj.v6i18.3070 
studies were found regarding the design of the physical classroom space. They were largely absent from the literature compared to the literature that addresses the origins, conditions, treatments, and pedagogical approaches for children with ASD (Martin, 2014). This research attempts to achieve the objective which to explore the relationship between the sensory design towards the physical learning environment for an autism classroom. Thus, the aim is to identify the criteria that have a strong significant relationship with the physical learning environment. Findings hoped to promote a conducive learning environment for autistic children. This would also help the technical agency and related government agencies used as a benchmark to design to improve the autism learning environment in Malaysia.

\subsection{Literature Review}

The built environment can be overwhelming, alienating, and challenging to negotiate with autistic children. This can act as a barrier to learning, hampering the child's development (Mcnally et al., 2013). The environment has a huge impact on a child with Sensory Sensitivity, also known as Sensory Processing Disorder or Sensory Integration Difficulty. Hence, creating spaces for them needs to consider precisely how to utilize the space since autistic people have different sensory needs, trouble understanding, and autistic people's brain processes stimulation (Raar, 2012). This section would elaborate on the sensory design approach, and the physical learning environment stipulates positively altering the sensory environment, which would improve and affect autistic academic outcomes.

\subsection{Sensory Design}

The sensory design approach is based on the sensory environment being a major role player in perception and behaviour (Gopal \& Raghavan, 2018). Hosny \& Anous (2015) mentioned that the Sensory Design Theory stipulates positively modifying the sensory environment; thus, the environment could be conducive to positive and constructive autistic behaviour, particularly in learning environments. The sensory design approach focuses on creating a controlled sensory environment that makes autistic people feel comfortable. Moreover, it offers a low stimulus environment, adaptable to severe autism and facilitates skill achievement (Hosny \& Anous, 2015). Sensory design is designed for living how a space feels, sounds, looks, smells, and functions, furthermore, to help autistic avoid feelings of anxiety, physical pain, and stress (Ghazali, Md Sakip, et al., 2018). The sensory design is beneficial to the autism learning environment by a modification to the surrounding environment. In the specific case of autistic children, the architectural design interventions used are broadly classified into the sensory design and neurotypical design approaches (Gopal \& Raghavan, 2018). The sensory design elements highlighted by Ghazali, Md Sakip, et al. (2018) comprises acoustic, spatial sequencing, escape space, compartmentation, transition zone, sensory zoning, and safety. As Ghazali, Md Sakip et al. (2018) reviewed, those elements are essential for the designer to experience the environment before designing autistic children's environments. While research done by Safrilia (2018) highlighted that the sensory design is called responsive architecture. In this case, the occupants and the environment are involved in the feelings, thoughts, and behaviour. The sensory design approach focuses on building occupants and paying close attention to how the room can affect them, both in the short and long term (Safrilia, 2018).

\subsection{Physical Learning Environment}

The learning environment refers to the space allocated for classrooms, science labs, open areas, and offices (Amirul et al., 2013; Che Ahmad \& Amirul, 2017). They defined the learning environment as the social context, psychological and pedagogical, which can affect students' learning, achievement, and attitudes. Research is done by Shaari \& Ahmad (2016) mentioned that the design process should consider the physical learning environment and concentrate on lesson planning and spatial arrangements, which is equally important. Shaari \& Ahmad (2016) stressed that children are influenced by their physical and social settings as it also affects children's behaviour, academic performance, and development. Not only concentrating on spatial arrangements, esthetic qualities, safety features, and appropriate use of material, finishes, and furniture contributes to conducive environments for teaching and learning (Shaari \& Ahmad, 2016). There exists a considerable of literature on the conduciveness of indoor environments such as thermal, visual, and acoustic comforts. Human comfort due to the physical environment affects a child's play behaviour, thus influencing learning (Shaari \& Ahmad, 2016). Besides the sensory issues, internal environment, sensory spaces, and the physical learning environment, it is great if the designer would look into the most potential that easily triggers the anxiety among autistic (Ghazali et al., 2019). The aspect of physical learning environment should be highlighted and discussed, such as the building entrance, building scale, safety and security, personal space and movement, wayfinding, legibility, threshold, classroom, quiet room, toilet, visual distraction, sun and glare, lighting, acoustic, smell, calm, low stimulus space, and sensory garden would create positive learning environment (Ghazali et al., 2019). Research by Che Ahmad \& Amirul (2017) highlighted that the physical aspects of the classroom environment's suitability were high for furniture and lighting facilities while the moderate level for air quality, colour, and space. Their research also addressed that the students perceived the physical learning environment impacts students' health, enjoyment, and learning. Furthermore, Che Ahmad \& Amirul (2017) revealed a significant relationship between the physical classroom environment and students' enjoyment and learning. Hence, the designer should consider the physical aspects of the classroom environment and give more attention to improving learning and teaching effectiveness.

\subsection{Relationship between Sensory Design and Physical Learning Environment}

Concerning sensory design, designing environments that make autistic children sensorily comfortable that help them involves exposure to as typical a real-world environment as possible (Gopal \& Raghavan, 2018). The sensory design approach is based on the concept that the sensory environment plays a major role in perception and behaviour to arrive at design interventions for sensory comfort of autistic children (Hosny \& Anous, 2015; Gopal \& Raghavan, 2018). To give autistic children sensorily comfortable, altering the sensory environment can be conducive to positive and constructive autistic behaviour, particularly in learning environments (Mostafa, 2014). In line 
with previous studies, constructing sensory design focuses on creating a controlled sensory environment that makes autistic people feel comfortable, facilitating skill acquirement (Hosny \& Anous, 2015). Furthermore, the typical perception as the understanding of, and relevant responding to, the sensory input from the surrounding environment (i.e. the architectural design), could better understand the role of architecture in autistic behaviour (Mostafa, 2014). The sensory design has demonstrated that autistic behaviour can be influenced favourably by altering the sensory environment and resulting from the physical architectural surroundings of colour, texture, ventilation, sense of closure, orientation, acoustics etc. (Mostafa, 2014). Hence, sensory design determined that designing for sensorily comfortable spaces could make the child more manageable, and formulated guidelines could aid the design process (Gopal \& Raghavan, 2018). Therefore, the consideration of sensory design is essential to improving environmental conditions. The influence on the physical environment could impact students' satisfaction, which then might lead to their performance (Munir, 2018). This study shows that those elements that appear consistent influence the physical learning environment by altering this sensory environment. Thus, in a manner designed to accommodate specific autistic needs by enhancing the sensory elements or creating a more conducive environment for more efficient skill development (Mostafa, 2014).

\subsection{Methodology}

The study is quantitative which employed the survey method to explore the relationship between the sensory design towards the physical learning environment for the autism classroom. This section describes the respondents, site study, instrument, and procedures.

\subsection{Respondents}

The questionnaire distributed to three hundred eighty-four (384) comprised people involved in the autism learning environment; they should be able to give opinions and may or may not experience designing or creating the autism learning environment. A total of three hundred fifty-four (354) respondents from the technical agency, thirty (30) interventionists and staff attached to Autism Centre.

\subsection{Site Study}

The study took place at the Autism Center, which is a pioneer autism centre in Malaysia that facilitate by the Malaysian government. The site selection was based on two main grounds. First, it is a pioneer autism centre and has become a benchmark. Second, it is early intervention and education to children with autism to prepare them for mainstream schools.

\subsection{Instrument}

The questionnaire consists of seven (7) sections - section one (1) was general information; section two (2) is about the rating scales using the Likert scale, which includes 1 for strongly disagree, 2 for disagree, 3 for neither agree nor disagree, 4 for agree and 5 for strongly agree; section three (3) was basically to generate the respondent demographic data; section four (4) is related to sensory sensitivity dealt with sight, sound, smell, taste, touch, proprioception and vestibular; section five (5) is related to sensory stimulation dealt with acoustic, colour, smell, lighting and visual; section six (6) is related to sensory design dealt with acoustic, spatial sequencing, escape space, compartmentation, transition zone, sensory zoning and safety, and finally section seven (7) is related to the physical learning environment dealt with building scale, accessibility, wayfinding, toilet provision, window, ventilation and heating, threshold, legibility, and furniture.

\subsection{Procedures}

Ethical permission was obtained from the administration of each agency before undergoing data collection. Due to pandemic covid-19, the participants will be given a set of questionnaires by email and informed consent to briefly explain the survey. Data was collected through a questionnaire that is self-administered by the respondents. The participants must respond to all questions, and finally, all the information about the participant is kept confidential.

\subsection{Data Analysis}

The raw data from the responses of each participant were coded numerically. Data were entered and analyzed using the Statistical Package for Social Sciences (SPSS) version 25 (SPSS Inc., Chicago, IL, USA) (SPSS, 2017). Descriptive statistic was used to examine the data collection. Several statistical tests were performed to assess the validity and reliability of the questionnaire. This was performed using Cronbach's alpha (a). An alpha between 0.70 and 0.95 was considered acceptable, and the significance level was set at 0.05 ( $a$ $<0.05)$ for all tests. The close-ended questionnaire had been analyzed by mean score, whereas Pearson's product-moment correlation coefficient was used to present this research's objective.

Pearson's product-moment correlation coefficient is the most extreme and standard index of the bivariate relationship or association between two variables (Pui Teng \& Hassan, 2015). Correlation is used to highlight relationships between the given variables (Owens, 2008). The researcher used correlation analysis to assess the relationship between sensory design (SD) and the physical learning environment (PLE). Before measuring the relationship, a correlation of -1 indicates a perfect linear descending relation with higher scores on one variable, implying lower scores on the other variable. A correlation of 0 means there is no linear relation between 2 variables whatsoever. However, there may be a (strong) non-linear relation, nevertheless. A correlation of 1 indicates a perfect ascending linear relation with higher scores on one variable associated with higher scores on the other variable (Au-Yong, 2013), as shown in Table 3.1. 
Table 4.1. Interpretation of Correlation (Au-Yong, 2013)

\begin{tabular}{cc}
\hline Value & Interpretation \\
\hline-1.00 & Perfect negative relationship \\
0 & No linear relationship exists \\
+1.00 & Perfect positive relationship \\
\hline
\end{tabular}

\subsection{Results}

This section focuses on the interpretation of the results. The first part is the respondent demographic background, and the second part is the findings of the Correlation of variables.

\subsection{Demographic Background}

Frequencies for the basic demographic were calculated. The demographic data showed that most respondents were female (61.5\%). Of these, $38.5 \%$ were males. Most of the respondents had an 11-15-year-old service duration (33.9\%), Those who had more than 15 years old service duration are $29.3 \%, 23 \%$ had service duration 6-10 years, and $13.8 \%$ participants had less than five years' service duration. Of the respondents who participated in the survey, $80.5 \%(n=140)$ participants were not involved in autism, and $19.5 \%$ ( $n=34)$ reported being involved in autism. Among the respondents who participated in the survey, $85.1 \%(n=148)$ reported that they do not have a family member with autism, and the remaining $14.9 \%(n=26)$ participants have a family member with autism.

\subsection{Correlation of Variables}

The study aimed to test the Correlation between sensory design (SD) and the physical learning environment (PLE) by using the Pearson correlation coefficient. There was a positive correlation between the two variables [ $r=.891, n=174, p<.0005]$. These findings show that the positive correlation between Sensory Design (SD) and the Physical Learning Environment (PLE) seems to have a strong relationship, as shown in the correlation coefficient result in Table 4.1.

\begin{tabular}{clcc}
\multicolumn{4}{c}{ Table 5.1. Pearson's Correlation Coefficient of SD and PLE } \\
\hline SD & Pearson Correlation & SD & PLE \\
\hline & Sig. (2-tailed) & 1 & $.891^{* *}$ \\
& $\mathrm{~N}$ & 174 & 0.000 \\
& Pearson Correlation & $.891^{* *}$ & 174 \\
\hline PLE & Sig. (2-tailed) & 0.000 & 1 \\
& $\mathrm{~N}$ & 174 & 174 \\
\hline${ }^{* *}$. Correlation is significant at the 0.01 level (2-tailed).
\end{tabular}

This finding indicates that sensory design affect the physical learning environment. Overall, the person involved in designing the sensory design elements should be given more attention to creating a conducive and comfortable learning environment.

\subsection{Discussion}

The 'alien' environment gives effect to a child with autism, either to be over-developed (hypersensitive) or under-developed (hyposensitive), which can result in feelings of anxiety, stress and physical pain (Ghazali et al., 2018b). As mentioned Ghazali, Md Sakip et al. (2018), the sensory design is focused on design for living which how a space feels, sounds, looks, smells, and functions, and it could be incredibly affecting one or more of the seven senses which can have an overwhelming effect on their life. Those criteria have a strong significant relationship with the physical learning environment in the context of autism. This study found that elements such as acoustic, spatial sequencing, escape space, compartmentation, transition zone, sensory zoning, safety, and security contribute to creating the Physical Learning Environment (PLE). In line with previous studies, the sensory design focuses on building occupants and paying close attention to how the room can affect autistic, both in the short and long term (Safrilia, 2018). Furthermore, it stipulates positively altering the sensory environment, conducive to positive and constructive autistic behaviour, particularly in learning environments (Safrilia, 2018). Hence, it focuses on creating a controlled sensory environment that makes autistic people feel comfortable and develop skill achievement (Safrilia, 2018).

\subsection{Conclusion \& Recommendations}

Our sensory design findings at least hint how this dimension is essential to the physical learning environment and affects user behaviour. This result highlights the elements that enhance the experience and wellbeing of autistic, through sensory design. It is hoped that it would provide pleasant spaces for all the autistic in a learning environment setting. These results indicate that sensory design attributes concerning its capacity to respond to the various autistic sensory needs (Mostafa, 2008). The applicability of this dimension explored by Ghazali et al. (2018b) on the impact of sensory design on autistic behaviour. It is shown that architects must design a physical learning environment to meet students' basic needs through acoustic, colour, smell, lighting, accessibility, wayfinding, compartmentation, the scale 
of the building, quiet room, safety, garden, etc. alternative. Hence, the exploration by Ghazali et al. (2018b) signifies the importance of paying attention to the physical learning environment in terms of sensory design such as physical building, internal environment, sensory issues, and sensory space. Designers should pay attention to the sensory design, and it is hoped that the physical learning environment would have less impact on autistic behaviour, less aggressive behaviours, and self-injury behaviour among autistics. It is proposed for future research to highlight the criteria of sensory design and physical learning environment. Apart from that, the observation approach would help the study to observe the real ambient of the autistic learning environment. Hence, emphasizing the criteria would help designers in creating a conducive environment for autistic children.

\subsection{Limitations}

The main limitation concern is data collection. It occurs during the pandemic Covid-19 and Movement Control Order (MCO) by the government. The study used email and online to conduct the survey. However, some respondents are more interested in meeting with researchers while responding to the questionnaire. Therefore, the researcher took quite a long time to get feedback from the respondents and approach them to respond to the questionnaires.

\section{Acknowledgement}

I would like to thank my supervisor Dr Siti Rasidah Md Sakip, and Asso. Prof. Dr Ismail Samsuddin for supporting me. Also, I would thank Jabatan Kerja Raya Malaysia for allowing me to further my study.

\section{Paper Contribution to Related Field of Study}

This study has incorporated a comprehensive literature review and identified the design criteria from previous scholars. There is a need for future research to investigate deep of each dimension and its effectiveness towards the modification of learning improvement. In addition, the researcher believes that there is room for further investigation by observation approach, which allows a continued enhancement of the autistic environment. It is hoped that this research paper would benefit the designer who involves in creating autism space. Perhaps, it gives a better understanding of sensory preferences that may enhance creating a conducive learning environment for autistic.

\section{References}

Amirul, N. J., Nidzam, C., Ahmad, C., Yahya, A., Faizal, M., Abdullah, N. L., Adnan, M., \& Noh, N. M. (2013). The physical classroom learning environment. 2nd International Higher Education Teaching and Learning Conference 2013, 9 pages.

Au-Yong, C. P. (2013). The Relationship Between Preventive Maintenance Characteristics and The Maintenance Performance of High-Rise Office Buildings in Malaysia. 305.

Che Ahmad, C. N., \& Amirul, N. J. (2017). The effect of the physical learning environment on students' health, enjoyment and learning. Jurnal Pendidikan Sains Dan Matematik Malaysia, 7(1), 47-55. https://doi.org/10.37134/jsspj.vol7.no1.4.2017

Ghazali, Md Sakip, \& Samsuddin. (2018). A Review of Sensory Design Physical Learning Environment for Autism Centre. E-IPH, AicQoL2018Perhentianlsland, 3(7), 7 pages. https://doi.org/10.21834/e-bpj.v3i7.1262

Ghazali, R., Md Sakip, S. R., \& Samsuddin, I. (2019). Creating Positive Environment for Autism Using Sensory Design. Environment-Behaviour Proceedings Journal, 4(10), 19. https://doi.org/10.21834/e-bpj.v4i10.1618

Ghazali, R., Sakip, S. R., \& Samsuddin, I. (2018). The Effects of Sensory Design on Autistic Children. Asian Journal of Behavioural Studies (AjBeS), 3(14), 68-83.

Gopal, A., \& Raghavan, J. (2018). Design interventions for Sensory comfort of Autistic children. Autism-Open Access, 08(01). https://doi.org/10.4172/21657890.1000227

Hosny, I., \& Anous, I. (2015). The impact of Interior Design in educational spaces for children with autism. American International Journal of Research in Humanities, Arts and Social Sciences, 15(329), 90-101. http://www.iasir.net

Martin, C. S. (2014). Exploring the impact of the design of the physical classroom environment on young children with autism spectrum disorder (ASD). Journal of Research in Special Educational Needs, 16(4), 19 pages. https://doi.org/10.1111/1471-3802.12092

Mcnally, H., Morris, D., \& Mcallister, K. (2013). Experiencing Primary School through the lens of the autistic spectrum. Aldo goes to Primary School (D. M. \& K. M. A. Hugh McNally (ed.)). McNally Morris Architects.

Mostafa. (2008). An Architecture for Autism: Concepts of Design Intervention for the Autistic User. International Journal of Architectural Research-IJAR, 2(1), 189-211.

Mostafa. (2014). Architecture For Autism: Autism ASPECTSS?? in School Design. International Journal of Architectural Research-Archnet-IJAR, 8(1), 143-158.

Munir, F. F. A. (2018). Reliability and Validity Analysis on the Relationship between Learning Space, Student's Satisfaction and Perceived Performance Using SMARTPLS. International Journal of Academic Research in Business and Social Sciences, 8(1), 772-783. https://doi.org/10.6007/lijarbss/v8-i1/3847 
Nazri, N. A., \& Ismail, Z. (2016). Educational building facilities for children with autism in Malaysia. Jurnal Teknologi. https://doi.org/10.11113/jt.v78.8489

Owens, K. (2008). UNDERSTANDING HOW ACTORS INFLUENCE POLICY IMPLEMENTATION: A comparative study of wetland restorations in New Jersy, Oregon, The Netherlands and Finland.

Pui Teng, W., \& Hassan, Z. (2015). The Influence of Transformational Leadership in Creating a Learning Organisation. International Journal of Accounting and Business Management, 3(1), 162-186. https://doi.org/10.24924/ijabm/2015.04/v3.iss1/162.186

Raar, E. (2012). Sensitive Design [Syracuse University]. https://surface.syr.edu/architecture_tpreps/192

Safrilia, A. (2018). Sensory Design: Hypersensitive and Hyposensitive Autism Rehabilitation Center in Malang. International Journal of Engineering Research \& Technology (IJERT), 6(December), 306-311. http://www.jjert.org

Shaari, M. F., \& Ahmad, S. S. (2016). Physical Learning Environment: Impact on Children School Readiness in Malaysian Preschools. Procedia - Social and Behavioral Sciences, 222, 9-18. https://doi.org/10.1016/j.sbspro.2016.05.164 